\title{
Respiratory Distress Syndrome
}

National Cancer Institute

\section{Source}

National Cancer Institute. Respiratory Distress Syndrome. NCI Thesaurus. Code C27560.

A condition beginning in the first day of life that results from inadequate surfactant

production, causing increased work of breathing and impaired gas exchange. 